\title{
Contrastive Study between Pronunciation Chinese L1 and English L2 from the Perspective of Interference Based on Observations in Genuine Teaching Contexts
}

\author{
Feng $\mathrm{Li}^{1}$ \\ ${ }^{1}$ School of Foreign Language, Jinling Institute of Technology, Nanjing, China \\ Correspondence: Feng Li, School of Foreign Language, Jinling Institute of Technology, Nanjing, China. Tel: \\ 86-189-1380-5880. E-mail: lifeng_7820@163.com
}

Received: August 3, 2016 Accepted: September 5, 2016 Online Published: September 8, 2016

doi: 10.5539/elt.v9n10p90 URL: http://dx.doi.org/10.5539/elt.v9n10p90

\begin{abstract}
Much research has been conducted on factors that impact on second language (L2) speech production in light of the age of L2 acquisition, the length of residence in the L2 environment, motivation, the amount of first language (L1) usage, etc. Very little of this research has taken the perspective of interference between L1 and L2, especially with respect to Asian languages. This article tries to locate the differences in pronunciation between Chinese L1 and English L2 by contrastive analysis through observing genuine teaching and learning contexts, in hope of facilitating English pronunciation pedagogy in China.
\end{abstract}

Keywords: interference, pronunciation, Chinese L1, English L2, observation

\section{Introduction}

Chinese and English fall into two entirely distinct language families. The former is ideographic while the latter is phonographic. They exhibit significant differences even in their phonological systems. The sound system of English includes two parts: segments and suprasegments. Segments include individual vowels and consonants, and suprasegments consist of stress, pitch contour or intonation, rhythm (Seferoglue, 2005). In Chinese, almost each character corresponds to a single syllable (Kelly, 2000), which may have an onset of consonant(s) initially in the syllable and a nucleus containing a vowel or two vowels or, in few cases, a vowel plus a final nasal consonant(s). For example, /la/, /lai/ and /lan/ are syllables with one consonant onset, while /sha/, /shai/ and /shang/ are ones with two-consonant onset. However, the absence of consonant onset is permitted in Chinese syllables as well: e.g., /a/, /e/, and /ai/ are common pronunciations of Chinese characters. Apart from that, another important characteristic of a Chinese syllable is, generally, its four tones: level (tone 1), rising (tone 2), falling-rising (tone 3), falling (tone 4). In Chinese, a tone plays an important role in distinguishing the meaning of Chinese characters (Zhao, 2006). For example, in the case of the same phonemes /ti/, if it is labelled with the four different tones, then four different meanings will arise. /tì/means "kick", /tí/ "question", /ť̃/ "body" while /tì/ carries the meaning of "substitute".

At the phonological level, Gui (1978) has explored the differences between Chinese and English, based on phonemes, tone, intonation, etc. Fan (1982) compared the sound systems of Chinese and English. He (2002) and Wei (2003) made contrastive studies on Chinese and English word stress patterns. However, these contrastive analyses are often criticized or challenged, for although they try to predict the possible transfer errors of language learners in L2, they are inadequate to predict the errors learners make in actual learning contexts (Whitman \& Jackson, 1972). This article aims to categorize transfer errors in pronunciation due to Chinese L1's interference on English L2 through observing genuine teaching and learning contexts, which may not exhaust all transfer errors in this case but definitely will elicit implications for English pedagogy in China.

\section{Literature Review}

The ability to understand spoken language is essential to the process of second language acquisition. One may easily understand the written words of a target language, but have difficulty identifying them in speech, due to the challenges of lexical segmentation or identifying word boundaries in auditory input. Foreign accents are very prominent in L2 speech production. Intelligible pronunciation plays a very important role for L2 learners, while unintelligible pronunciation inhibits successful communication with native speakers even for those with a 
sizeable vocabulary and a correct grammar.

Both researchers and instructors have adopted various approaches to teaching pronunciation. In recent years, there has been renewed interest in pronunciation. Pronunciation research has been dominated by a strong interest in quantitative investigations of the development of learners' proficiency as a result of inhabiting different learning environments (e.g., Díaz-Campos, 2004; O’Brien, 2003, 2004; Simões, 1996; Stevens, 2000) and teaching strategies by measuring specific phonetic elements according to native-speaker norms (e.g., D. Macdonald, Yule, \& Powers, 1994). Few, if any, studies have thus far investigated the teaching and learning of pronunciation from the perspective of interference between L1 and L2. Many studies (Best, 1995; Best, McRoberts, and Goodell, 2001; Flege, 1995; Flege, Frieda, \& Nozawa, 1997; Gass and Selinker, 2001; Kuhl et at., 1992) have substantiated that numerous factors can affect L2 speech production, such as the age of L2 acquisition, the length of residence in the L2 environment, motivation, and the amount of L1 usage. However, according to Flege's study (1995), L1's effect on L2 speech production is especially noteworthy (and as we will document, this is particularly clear in native Chinese speakers learning English).

The difficulties facing a second language learner concern phonology, vocabulary and grammar, as a result of the interference of habits from L1 onto L2 (Beardsmore, 1982). Interference is the result of old habits of the first language, which must be unlearned before acquiring new habits in the second language (Dualy, Burt, \& Krashen, 1982). Selinker (1983) points out that there are two types of transfer in learning a second language: positive and negative. Where the two languages are partly identical or similar, learning can take place easily through the positive transfer of a native language pattern, but where they are different, learning difficulties arise, and errors resulting from negative transfer are likely to occur (Ellis, 1994). As Odlin (1989) points out, when negative transfer occurs, we can study learners of different native languages and compare them to find out the effect of L1 in learning a second language L2. According to a literature review on teaching pronunciation by Wei (2006), although English has become more disseminated globally and the importance of pedagogies for English has increased, pronunciation teaching is still not afforded enough attention, especially in English education in Asian countries. This article aims to contrast Chinese L1 and English L2 with respect to their pronunciation in genuine teaching and learning contexts, so as to determine the underlying negative transfers and to categorize the transfer errors in speech production. The greater the differences between two languages will result in a greater difficulty for learners (Hayati, 1998). With the knowledge of differences in pronunciation between Chinese L1 and English L2, we may be able to improve students' English pronunciation by reinforced practice in the aspects concerned.

\section{Contrastive Analysis and Findings based on Observations}

\subsection{Consonants: $/ \delta /, / \theta /$ and $/ \nu /$}

For those sounds that Chinese has which have similar counterparts in English, Chinese L1 students when learning English can acquire them with ease, such as $/ \mathrm{b} /, / \mathrm{p} /, / \mathrm{d} /, / \mathrm{t} /, / \mathrm{g} /$ and $/ \mathrm{k} /$. But the sounds $/ \mathrm{d} /, / \theta /$ and $/ \mathrm{v} /$ don't exist in Chinese, and Chinese L1 students find then quite difficult to produce. Especially in the case of $/ \delta /$ and $/ \theta /$, to speak with your tongue exposed appears very amusing, or even humiliating, in Chinese speech. However, the two sounds occur in English pronunciation frequently, such as 'I think', 'this', 'that', etc. If they don't practice these sounds, Chinese L1 students tend to produce them into $/ \mathrm{z} /$ and $/ \mathrm{s} /$. So, it is very common to hear Chinese L1 students say "I sink" instead of "I think" in an English conversation, and many Chinese L1 students say "my mouse" when they actually intend to say "my mouth". The sound /v/ doesn't appear in Chinese pronunciation as well, which tends to be substituted for by the sound of $/ \mathrm{w} /$ in Chinese utterances. For instance, /'veri/ (very) is mistaken for /'weri/, and /vet/ for /wet/, which probably contributes to misunderstanding in communication with English speakers. Interestingly, even though certain English sounds of vowels can be found in Chinese, due to slight and subtle differences among them, some Chinese L1 students find it hard to distinguish

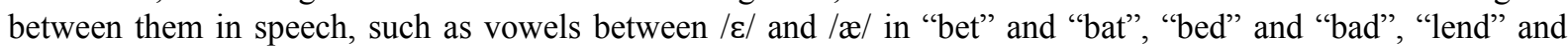
"land", "dead" and "dad", "merry" and "marry", etc., especially when they appear in the same discourse, or even in the same sentence, which will absolutely produce an effect of tongue twisters. Another pair of vowels difficult for Chinese L1 students to distinguish is $/ \Lambda /$ and /a/ as in "shut" and "shot", "bus" and "boss", "gun" and "gone", "lung" and "long".

\subsection{Long Vowels}

In English pronunciation, there are short and long vowels. The long vowel in /liv/ (leave) creates a different meaning than the short one in /liv/ (live). You can eat the fruit of a /pitf/ (peach) rather than a /prtf/ (pitch). Short vowels and long vowels can provoke a difference in meaning for English words. Nevertheless, although its syllable may be comprised of consonant(s) and vowel(s), each Chinese character is articulated at a similar rate or length, that is, no matter how long the syllable is, it only has one articulated sound. Usually, we prolong some 
characters' articulation only when reading poems out loud. Even if it is prolonged in articulation, a Chinese character doesn't change its meaning. Chinese speakers, especially in the south of China, are accustomed to producing brief speech sounds. Therefore, the long vowels of English L2 do not easily become part of the repertoire of Chinese L1 pronunciation. Accordingly, Chinese students are likely to mix up their pronunciations when they confront such pairs as/I/ and $/ \mathrm{i} /, / \mathrm{a} /$ and $/ \mathrm{J} /, / \Lambda /$ and $/ \mathrm{a} /$, and $/ \mathrm{v} / \mathrm{and} / \mathrm{u} /$. Detailed examples are listed below to facilitate a clear understanding.

$/ \mathrm{I} /$ and $/ \mathrm{i} /$

bit, beat

wit, wheat

fit, feet

pill, peel

dip, deep

mill, meal

knit, neat

list, least

ship, sheep

/a/ and $/ \mathrm{J} /$

shot, short

pot, port

swan, sworn

not, naught

fox, forks

cock, cork

spot, sport

$/ \mathrm{A} /$ and / $/ \mathrm{a} /$

bun, barn

but, heart

cut, cart

come, calm

guts, guards

must, master

lust, last

much, march

tusk, task

$/ \mathrm{v} /$ and $/ \mathrm{u} /$

book, boot

good, food

foot, food

shook, shoot

stood, stool

full, fool

The last pair of words, "full" and fool", is the most confusing one for Chinese L1 students. When saying 'I am full' after a meal, they fear that their listeners may misunderstand as to be saying, 'I am a fool'. 


\subsection{Diphthongs}

There are (almost) no such sounds in Chinese as diphthongs, though we may find two vowels together comprising the nucleus in the syllable of one Chinese character, such as /hua/, /xia/, etc. However, as I mentioned above, regardless of the length of the syllable, the final speech sound of a Chinese character is only one short sound, while in English, almost all the phonemes which contribute to the pronunciation of one word can be perceived by listeners, no matter whether its speech production is as short as one syllable or as long as two or more syllables. Such words as "downtown", "now" and "how" involve moving from one vowel to the next different vowel, which is unusual in Chinese pronunciation. Consequently, it is hard for native Chinese speakers to pronounce English words with a diphthong correctly and fully. They must practice them before they can pronounce them correctly. Even so, Chinese native speakers' pronunciations of English words with diphthongs still sound odd or off. Undoubtedly, in this case, Chinese L1 students make full use of the similar pronunciations in their mother tongue. It is quite common to hear some Chinese students greet with "/ha/ (how) are you" rather than "/hau/ are you", for they feel comfortable in producing the sound /a/ instead of /au/. Obviously, when producing diphthongs, Chinese L1 students prefer to substitute single vowels for diphthongs. The production of diphthongs reveals some very salient interference between Chinese L1 and English L2, and so, great importance should be attached to it when teaching English. The following pairs are some illustrations Chinese L1 students may mix up.

$/ \varepsilon /$ and $/ \mathrm{ei} /$

pen, pain

get, gate

pepper, paper

let, late

tell, tail

wet, wait

sell, sale

fell, fail

said, say

/eI/ and /I/

gave, give

stale, still

chain, chin

wait, wit

fail, fill

case, kill

sake, sick

pain, pin

whale, will

/a/ and /ai/

bar, buy

darn, dine

lark, like

cart, kite

heart, height

laugh, life

/ai/ and /æ/

bike, back 
fight, fat

glide, glad

kite, cat

fine, fan

$/ \partial \mathrm{o} /$ and $/ \mathrm{J} /$

coke, cork

bowl, ball

woke, walk

toe, tore

boat, bought

/a/ and /av/

bar, bow

car, cow

dart, doubt

art, out

/av/ and /a/

found, fond

pound, pond

mouse, moss

down, don

bound, bond

trout, trot

cloud, clod

/u/ and /v3/

two, tour

shoe, sure

pull, poor

/eI/, /av/ and /uz/ are invariably found to be the most difficult diphthongs to pronounce for Chinese L1 students.

\subsection{Consonant Ending}

Many English words are pronounced with consonant endings, even with consonant clusters, such as "horse", "lock", "desk", and "prompt". These English words present a difficulty for Chinese L1 students when learning spoken English, for the pronunciation of many Chinese characters ends with vowels, such as /zhuō zi/ (desk) and /mŭ jī/ (hen), and there are only some exceptions, for instance, with the nasal consonant $/ \mathrm{n} / \mathrm{or} / \mathrm{y} /$, as in $/ \mathrm{shān} /$ (hill) and /xióng/ (bear). Therefore, Chinese speakers are not accustomed to pronunciations with consonant endings, and so, tend to adjust their pronunciations to a more Chinese way. Take "pig" and "dog," for example. Chinese L1 students are inclined to pronounce them as /prga / and /dogo/. We add the vowel /a/ to a word with consonant(s) ending because otherwise we would fear we hadn't made ourselves heard and understood. Unfortunately, such pronunciation with Chinese characteristics may often provoke misunderstanding or confusion in communication.

\subsection{The Retroflex Sound / $/$ /}

This retroflex sound / $\mathrm{r}$ / in English pronunciation is easy for Arabic or Indian speakers, because they can twist their tongues; indeed, sometimes we cannot catch the sounds they are producing. Unfortunately, for Chinese L1 students, the retroflex sound is like a punishment to the tongue, especially when the sound is at the end of a word's pronunciation, like "floor", "moor", 'teacher" and "doctor". Without sufficient practice, Chinese L1 students will produce a non-full sound of /r/, or even just drop the ending sound of $/ \mathrm{r} /$ altogether. However, when $/ \mathrm{r} /$ is placed in positions in a word other than the ending, most Chinese L1 students can produce it correctly, such 
as "rice", "rose", "grow" and "fright".

\subsection{Stress of Words}

Every Chinese character usually has a one-syllabic sound, which is short and easy to produce. So, generally, Chinese L1 students do not need to worry about stress when pronouncing a Chinese character. However, there are many words in English with multiple syllables. Some Chinese students are at a loss when confronted by stress in multi-syllabic English words. No stress, or the wrong placement of stress, can mean something different, or perhaps even nothing at all in English. The same word may experience class changes or even meaning changes when stress placement shifts from the first syllable to the second.

Some evidence is listed as below:

Class changes

contrast,

discount

export

import

ferment

increase

insult

permit

progress

protest

Meaning changes

produce

rebel

record

suspect

frequent

digest

present

minute

subject

object

conduct

content

desert

Interestedly, some Chinese L1 students do realize that a change of stress placement can cause a change of word class, generally, between nouns and verbs, and accordingly, they have a tendency to over generalize this phenomenon, resulting in error. For example, they might say "excuse / $1 \mathrm{k}$ 'skjus/ me" with correct stress placement, but tend to say "This is an excuse /'ekskjus/," misplacing the stress on the first syllable. After they find themselves making this mistake, confusion inevitably arises.

\subsection{Intonation}

American English speakers like to speak with an exaggerated emotional rising intonation. (And Americans also manifest vivid and interesting facial expressions.) Chinese L1 students usually speak calmly with a flat intonation, which may come across as cold to some Americans. Textbooks teach us:

General questions are pronounced with a rising intonation:

Can you speak English $\nearrow$ ? 
Alternative questions are pronounced with a rising-falling intonation:

Can you speak English $\nearrow$ or Chinese $\searrow$ ?

Wh-questions are pronounced with a falling intonation:

What language can you speak $\searrow$ ?

And affirmative or negative sentences are all pronounced with falling intonation:

She can speak English \, but can’t speak Chinese \.

However, in reality, American speakers can produce a variety of intonations even of the same expression in different situations or in different moods, which is normally not part of grammar proper. Take "yes" for example.

1). We must know our own history. Do you agree?

Yes, I do. (general agreement)

2). (Entering the office) Professor Lepore?

Yes? (What's up? Nicely)

3). May I borrow your phone?

Yes. But it's not here with me. (tentativeness)

4). You look very exhausted.

Yes. Didn't sleep well last night. (laziness)

5). May I have the next dance with you, Li?

Yes. (excitement)

6). This afternoon we'll beat them in the semi-final.

Yes. (enthusiasm)

7). Your son seems to be busy all the time.

Yes, busy with computer games. (irony)

8). Are you free tonight?

Yes. (question)

Oh, I just wonder.

9). Don't forget to take the medicine before you go.

Yes, Mom. You've said it ten times. (impatience)

10). Do you like the dress?

Yes, but it's too expensive. (reservations)

11). So you don't like that book?

Yes, I do! (emphasis)

Chinese students can understand the variations in meaning or attitude or emotion of one English expression quite well in most cases, but it's very difficult for them to imitate or acquire English speakers' intonations, which, quite different from Chinese intonations, make them feel unnatural, embarrassed and even insincere in communication. Exaggerated English speakers' intonations go against their habitual Chinese speaking intonations, which are nurtured by their own culture. This is probably the greatest difficulty for Chinese L1 students in learning to speak English in a native way, for to remove habits developed by one's culture is not fulfilled easily in a short period, especially when they still live within their culture.

\subsection{Segmentation}

Everyone finds it difficult to ascertain where one word ends and the next begins in speech while learning a foreign language. Sometimes Chinese L1 students can't speak in a native way, or can't understand what a native speaker produces, which probably results from segmentation of a sentence. Chinese characters are usually isolated in pronunciation even when they occur next to each other except for a very few cases, while there are many liaisons and plosives in English pronunciation, which creates great obstacles for Chinese L1 students when they try to individuate each word in a sentence. For example, they may mistake "get up" for "ge tup", or "come in" for "coming", or "sit down" for "sea down". Native English speakers and Chinese L1 students probably will 
produce a little bit different sounds when they read liaisons and plosives such as:

Liaison
come in
keep on
get up
hold up
stand up
above all
best of all
first of all
not at all
all of us
Plosives
lap top
keep quiet
sit down
get together
get back
good time
next door
good guy
wet paint

So, sometimes it is hard to know whether one is hearing "The sky is blue" versus "This guy is blue". When this happens, Chinese L1 speakers have to retrieve from their mental lexicon what these words mean, because it is not what they have learned, even though these strings sound familiar. This process of retrieval takes listeners more time to comprehend, which, in turn, impacts on communication negatively.

\section{Implications for English pronunciation Teaching}

Pronunciation is a set of habits or conventions to produce sounds. Learning to pronounce the expressions of a second language means acquiring new pronunciation habits and overcoming the biases of the first language (Cook, 1996). For this purpose, more attention should be drawn to how to go about teaching pronunciation effectively. Base on the observations and analyses of the genuine English teaching in China, two implications for teaching English pronunciation are put forward here.

4.1 In the Case of Segmental Features, Placing More Emphasis on Some Phonemes Where Chinese L1 May Exert Negative Transfer on English L2

Many researchers have affirmed the importance of the supra-segmental feature for communication, rather than segmental features, because they think the former can more significantly impact the intelligibility and comprehensibility of English (e.g., Morley, 1991; Munro \& Derwing, 1995; Levis, 1999; Hahn, 2002). But for the Chinese L1 students, once they are affected by the negative transfer of their mother tongue onto such phonemes as $/ \mathrm{d} /, / \theta /, / \mathrm{v} /$, long vowels, diphthongs, consonant(s) endings, they may not be able to make themselves understood, or even worse, they may make themselves misunderstood, which very likely will contribute to unintelligibility and incomprehensibility as well. In the City of Nanjing China, people cannot distinguish between the sounds $/ 1 /$ and $/ \mathrm{n} /$. When teaching students of Nanjing, therefore, English teachers must place greater emphasis on these phonemes besides the ones discussed above, for fear that they might mistakenly produce the sentence "you are lice" rather than "you are nice". So, it is essential to enforce the regular practice of some phonemes that may be subject to negative transfer of Chinese L1 in teaching English.

Other examples are listed below.

low, know 
light, night

lot, not

lead, need

life, knife

lice, nice

lest, nest

lease, niece

slow, snow

4.2 In the Case of Supra-Segmental Features, Placing More Emphasis on Stress, Intonation and Sentence Segmentation Which Chinese L1 is Lack of

A broad definition of pronunciation includes both segmental features and supra-segmental features. Their combination promotes better communication. Therefore, they should be learned as an integral part of spoken language. As English teachers, we should remind students of the different aspects of English in terms of supra-segments such as stress, intonation and segmentation. While bearing these differences in mind, they can make progress through more reading, more listening, and more imitation. Why is it important for students to be informed of these differences? Most Chinese students' pronunciation is found dissatisfactory even when they come to college. Many of them do not realize that there are liaisons and plosives in English pronunciation. They tend to speak English almost word by word, unconscious of stressed or unstressed parts of a sentence, let alone intonation, which make their English speaking and listening awkward. However, it is hard to correct and improve their pronunciation in college due to fossilization, even if much time and energy has been taken. Had they been informed of these facts at the beginning of their English learning, their English would be better, at least their English pronunciation would be.

In teaching intonation, certain beliefs should be established among students in addition to promoting practice. They should hold the belief that speaking English in a native way is fun rather than unnatural or humiliating; speaking English in a native way is beneficial to effective communication. Students are supposed to know Americans exaggerated intonation, understand it, accept it, identify with it, and then, acquire it, since they are learning the language. In this case, due to cultural differences involved, more effort ought to be placed on teaching pronunciation.

Being qualified for English pronunciation instruction requires not only being able to speak English correctly, fluently and natively, but also being able to build up or categorize the knowledge of difficulties in English pronunciation for Chinese L1 students, because being able to do the latter will greatly facilitate English instruction and learning.

\section{Conclusion}

Rightly or wrongly, Goodwin (2001) stresses that L2 proficiency is most likely judged through pronunciation. Unintelligible pronunciation prevents even those with an abundant vocabulary and an accurate grammar from successful communication with L1 speakers. This article is intended to reveal differences in pronunciation between Chinese L1 and English L2, as well as to identify the underlying interference that Chinese L1 may have on English L2, in the hopes of decreasing Chinese L1 negative transfer while acquiring English L2 pronunciation.

L2 learners usually substitute the L1 phones for similar L2 ones. In other words, rather than create a new sound category, L2 learners substitute the closest L1 counterpart they can find. Therefore, it is essential for an English teacher in China to have an accurate grasp of both the English and the Chinese phonological systems in order to enhance the quality of pronunciation as well as to lessen Chinese L1's interference on English L2. Through the contrastive analysis above, this article shows that some segmental and supra-segmental errors may occur to Chinese L1 students because of a lack of sounds or differences in speech production in Chinese. For an English teacher in China, having such knowledge can be quite advantageous, especially when the teacher desires to improve student pronunciation of English.

\section{Acknowledgement}

This research has been sponsored by 2015 Jiangsu Overseas Research \& Training Program for University Prominent Young \& Middle-aged Teachers and Presidents. 


\section{References}

Beardsmore, H. B. (1982). Bilingualism. Tieto: Avon.

Best, C. (1995). A direct realist view of cross-language speech perception. In W. Strange (Ed.), Speech perception and linguistics experience: Theoretical and mythological issues in cross-language speech research 109(2) (pp. 775-794). Timonium, MD: York Press.

Best, C., McRoberts, G., \& Goodell, E. (2001). Discrimination of non-native consonant contrasts varying on perceptual assimilation to the listener's native phonological system. Acoustical Society of America, 109(2), 775-794. http://dx.doi.org/10.1121/1.1332378

Cook, V. (1996). Second language learning and language teaching. London: Arnold.

Díaz-Campos, M. (2004). Context of learning in the acquisition of Spanish second language phonology. Studies in Second Language Acquisition, 19, 1-16. http://dx.doi.org/10.1017/s0272263104262052

Dulay, H., Burt, M., \& Krashen, S. (1982). Language two. New York: Oxford University Press.

Ellis, R. (1994). The study of second language acquisition. Oxford: Oxford University Press.

Fan, C. Z. (1982). Sounds of English and Chinese. Primary and Middle School English Teaching and Research, $1,3-4$.

Flege, J. (1995). Second language speech learning. In W. Strange (Ed.), Speech perception and linguistic experience: Issues in cross-language research (pp. 233-277). Timonium, MD: York Press.

Flege, J., Frieda, E., \& Nozawa, T. (1997). Amount of Native language (L1 use) affects the pronunciation of an L2. Journal of Phonetics, 25, 169-186. http://dx.doi.org/10.1006/jpho.1996.0040

Gass, S., \& Selinker, L. (2001). Second language acquisition. Mahwah, NJ: Lawrence Erlbaum.

Goodwin, J. (2001). Teaching pronunciation. In Celce-Murcis (Ed.), Teaching English as a Second Language (pp. 117-138). Heinle \& Hernle.

Gui, C. K. (1978). A comparison of Chinese and English sound system. Modern Foreign Languages, 1, 44-50.

Hahn, L. (2004). Primary stress and intelligibility: research to motivate the teaching of supra-segmentals. TESOL Quarterly, 38, 201-223. http://dx.doi.org/10.2307/3588378

Hayati, M. (1998). A contrastive analysis of English and Persian stress. Papers and Studies in Contrastive Linguistics, 34, 53-72.

He, S. F. (2002). Contrastive analysis of English and Chinese. Shanghai: Shanghai Foreign Language Education Press.

Kelly, G. (2000). How to teach pronunciation. Harlow: Longman.

Kuhl, P., Wiliams, K., Lacerda, F., Stevens, K., \& Lindblom, B. (1992). Linguistics experience alters phonetic perception on infants by six months of age. Science, 255, 606-608. http://dx.doi.org/10.1126/science.1736364

Levis, J. (1999). Intonation in theory and practice, revisited. TESOL Quarterly, 33, 37-63. http://dx.doi.org/10.2307/3588190

Morley, J. (1991). The pronunciation component in teaching English to speakers of other languages. TESOL Quarterly, 25, 481-521. http://dx.doi.org/10.2307/3586981

Munro, M. J., \& Derwing, T. M. (1995). Foreign accent, comprehensibility, and intelligibility in the speech of $\begin{array}{lllll}\text { second language } & \text { learners. } & \text { Language } & \text { Learning, } & 45,\end{array}$ http://dx.doi.org/10.1111/j.1467-1770.1995.tb00963.x

O’Brien, M. G. (2003). Longitudinal development of second language German vowels (Unpublished doctoral dissertation). University of Wisconsin-Madison. Retrieved from ProQuest Dissertations and Theses (UMI No. 3089612).

O’Brien, M. G. (2004). Pronunciation matters. Unterrichtspraxis, 37, 1-9. http://dx.doi.org/10.1111/j.1756-1221.2004.tb00068.x

Odline, T. (1989). Language transfer: Cross-linguistic influence in language learning. Cambridge: Cambridge University Press. http://dx.doi.org/10.1017/CBO9781139524537

Selinker, L. (1983). Language transfer. In S. Gass, \& L. Selinker (Eds.), Language transfer in language learning 
(pp. 33-68). Rowley, MA: Newbury House.

Simões, A. R. M. (1996). Phonetics in second language acquisition: An acoustic study of fluency in adult learners of Spanish. Hispania, 79, 87-95. http://dx.doi.org/10.2307/345617

Seferoglue, G. (2005). Improving students' pronunciation through accent reduction software. Brithish Journal of Educational Technology, 36(2), 303-316. http://dx.doi.org/10.1111/j.1467-8535.2005.00459.x

Stevens, J. J. (2000). The acquisition of L2 Spanish pronunciation in a study abroad context (Unpublished doctoral dissertation). University of Southern California. Retrieved from ProQuest Dissertations and Theses (UMI No. 3018129).

Wei, M. (2006). A literature review on strategies for teaching pronunciation. Retrieved from http://newfirstsearch. oclc.org

Wei, Z. C. (2003). An introduction to comparative studies of Chinese and English. Shanghai: Shanghai Foreign Language Education Press.

Whitman, R., \& Jackson, K. (1972). The unpredictability of contrastive analysis. Language Learning, 22, $29-41$. http://dx.doi.org/10.1111/j.1467-1770.1972.tb00071.x

Zhao, Z. D. (2006). Phonology. Shanghai Foreign Language Education Press.

\section{Copyrights}

Copyright for this article is retained by the author(s), with first publication rights granted to the journal.

This is an open-access article distributed under the terms and conditions of the Creative Commons Attribution license (http://creativecommons.org/licenses/by/4.0/). 